
3 Research Square
Preprints are preliminary reports that have not undergone peer review.
They should not be considered conclusive, used to inform clinical practice, or referenced by the media as validated information.

\title{
Is it necessary for suspected children with coronavirus disease-2019(COVID-19) to perform CT scan?
}

Chen Qiyi ( $\square$ 13488725189@139.com )

Beijing Ditan Hospital Affiliated Capital Medical College https://orcid.org/0000-0001-8822-3839

\section{Xie Ruming}

Beijing Ditan Hospital Affiliated Capital Medical College https://orcid.org/0000-0002-1727-4556

Chen Hui

Beijing Ditan Hospital Affiliated Capital Medical College https://orcid.org/0000-0002-0108-9874

Wang Yajie

Beijing Ditan Hospital Affiliated Capital Medical College https://orcid.org/0000-0002-7023-4844

\section{Chen Budong}

Beijing Ditan Hospital Affiliated Capital Medical College https://orcid.org/0000-0002-4412-1387

\section{Research Article}

Keywords: COVID-19, COV-SARS-2, computed tomography, nucleic acid assays

Posted Date: June 30th, 2020

DOI: https://doi.org/10.21203/rs.3.rs-39081/v1

License: (c) (1) This work is licensed under a Creative Commons Attribution 4.0 International License. Read Full License 


\section{Abstract}

Objectives: the aim is to evaluate justification for suspected children withcoronavirus disease-2019 (COVID-19) to perform CT scanning.

Methods: Eighteen suspected children ( 7 male and 11 female) accepted both CT scanning (except one) and then pharyngeal swab assays from 26th January to 9th March 2020 in the retrospective study. They were confirmed COVID-19 by twice positive test and divided into two groups: asymptomatic subgroup and symptomatic subgroup. Fisher`s exact test was used in statistical analysis.

Results: The CT positive ratio was not significant in the two subgroups ( $0(0 \%)$ vs $3(23.1 \%), p=0.541)$, the same as that in different sex and ages (female vs male: $2(20.0 \%)$ vs $1(14.3 \%), p=1.000 ;<=3$ years vs $>3$ years: $2(28.6 \%)$ vs $1(10.0 \%), p=0.537)$. The demonstrations of the two positive CT were multiple patchy infiltration or ill-fined ground-glass opacity in subpleural regions.

Conclusions: It was unnecessary for suspected children with COVID-19 to perform CT scanning as a "routine" ahead of viral nucleic acid assays.

\section{Introduction}

Coronavirus 2 seriously attacked China in the traditional spring festival eve of 2020. Person-to-person transmission evidently aggravated the disaster. Ever before some time, as Lee PI's perspectives, children were less susceptible to COVID-19[1]. So little information about pediatric with COVID-19 was known. However, as familial cluster reports came to our view, pediatric cases become the focus to doctors. The neonatal cases was usually asymptomatic[2-4], but with high viral load[4]. the children cases were mild or asymptomatic as neonates as it was shown in a review[3]. Wei Xia etc. declaimed that pediatric patients with COVID-19 shared "different" clinical and radiological features, but 20\% was normal[5]. Similarly, another report showed two in five children with normal chest CT[6]. Some study found that CT findings might preceded symptoms in asymptomatic adult patients and showed the necessity of CT examination in this circumstance[7, 8]. Was it so for suspected children to perform CT scanning before nucleic acid test results indeed? In this study, the aim was to justify whether is it necessary for suspected children with COVID-19 to perform computed tomography ahead of viral nucleic acid assays.

\section{Materials And Methods}

Subjects

Eighteen suspected children, both accepted CT scanning (except one) and pharyngeal swab assays, were included from 26th January to 9th March 2020 in the retrospective study. They were confirmed COVID19 by twice positive test and divided into two groups: asymptomatic subgroup and symptomatic subgroup. There were 7 male $(7 / 18,39 \%)$ and 11 female $(11 / 18,61 \%)$. Their ages ranged from three months 17 days to 13 years 11 months, with a median age of 5 years and 8 months. The diagnostic 
criterion referred to the "Diagnosis and Treatment Protocol for COVID-19 (6 $6^{\text {th }}$ and $7^{\text {th }}$ Revised Edition)" developed by the National Health Commission[9].

CT scanning and reading

All plain CT scanning was performed on SIMENS Emotion 16 unit (Siemens medical system; Siemens, Germany) with the following parameters: $110 \mathrm{kV}$, automatic mAs, $0.5 \mathrm{~mm}$ collimation, and 1.2:1 pitch. The scanning range covered from lung apex to diaphragm on axial plane performed by free-breath with supine position. High resolution reconstruction with $1.5 \mathrm{~mm}$ collimation with a standard algorithm and then the imagines were sent to the Picture Archiving and Communication System (PACS). CT images reading was in a lung window with Window Center (WC) -560 HU and Window Width (WW) $1550 \mathrm{HU}$, and a mediastinum window with Window Center (WC) $40 \mathrm{HU}$ and Window Width (WW) $400 \mathrm{HU}$. All the images were stored in PACS and reviewed by two experienced pediatric radiologists.

Statistical analysis

All data were computed via IBM SPSS Statistics vision 20.0. Kappa coefficient was used to assess interreader variability. Fisher's exact test was used to comparison in different groups. Mann-Whitney U test was used for skewed distribution data in different groups. $\mathrm{P}<0.05$ was considered as the threshold for statistical significance.

\section{Results}

These patients were mild or asymptomatic. Their diagnostic time and CT positive ratio showed no significance between asymptomatic and symptomatic group(table 1). The medial hospitalized duration was 14.5 days (range 9 to 23 days) and 31.0 days (range 17 to 45 days) in the two groups (MannWhitney $U=12.500, p=0.932$ ). The $C T$ positive ratios between different sex and age groups also show no significance (female vs male: $2(20.0 \%)$ vs $1(14.3 \%), p=1.000 ;<=3$ years vs $>3$ years: $2(28.6 \%)$ vs 1 (10.0\%), $p=0.537$ ). It showed good consistence between inter-readers (Kappa $=0.767, p=0.001$ ), too. The eighteen patients were intermittently positive with pharyngeal swab and/or sputum sample during hospitalized time (figure 1).

Two patients were apparent abnormal in CT imaging. The demonstrations of their ches CT were multiple patchy infiltration or ill-fined ground-glass opacity in subpleural regions. Their imaging demonstrations displayed in figure 2 and 3 . Another patient was susceptible in CT imaging because of artifacts overlapped.

\section{Discussion}

The characteristic demonstrations of COVID-19 in chest CT image help radiologist to diagnosis in adults[10], especially for asymptomatic patient[7]. Some researchers put forward the viewpoint of " different " CT features of pediatrics from that of adults[11]. in this study, the CT demonstrations of two 
positive children were not different from that of adults. Moreover, it was not negligible for us that a proportion of them were negative in chest CT. In the observational study, the negative CT ratio was larger than that in literature. It might be due to CT scan in early stage and lower respiratory tracts was free. the positive performance shared the similar features not as previous reports. In this study, influenza A in a child might make his abnormal CT performance unclear. In this complicated condition, chest CT might be necessary to perform, just as Chinese pediatrics' experts declared that CT performance was essential in differentiation of complications[12].

Everyone was vulnerable to coronavirus 2 (COV-SARS-2) rather than susceptible to older adult men, particularly those with chronic comorbidities[13]. Nonetheless, pediatrics with COVID-19 were usually mild or even asymptomatic[14]. The same results were shown as above in this study. Why was that in pediatrics rather than in adults? The angiotensin-converting enzyme-2 (ACE2), a viral receptor[15], might play an important role in resistance to COV-SARS-2. It varied in distribution, maturation, and functioning and expressed with age-related decrease[16], which was a possible reason. Additionally, children have a more active innate immune response, healthier respiratory tracts.

Although they were asymptomatic, high viral load was gotten in pharyngeal swab specimen[17]. Besides, because of delayed clearance of viral RNA in patients' stools compared to that in oropharyngeal swabs, it is important to identify viral RNA in feces during convalescence. The duration of RNA detection may relate to host cell immunity[12]. In this study, nucleic acid test was also intermittently positive in two samples during hospitalized time. So it is necessary to test in different time and different samples either in hospitalized time or convalescence.

Dose length product (DLP) was not archived in the PACS system. it was impossible to evaluate the index in the study. The small sample size was also a limit.

\section{Conclusions}

Suspected children with COVID-19 was wild or asymptomatic, so it was unnecessary to perform CT scanning as a "routine" ahead of viral nucleic acid assays.

\section{Declarations}

\section{Ethic Approval}

The protocol for this retrospective study was approved by the Ethics Committee of Hospital and the written informed consent was waived for emerging infectious diseases. The protocol number of the ethics committee approval: 2020-022-01.

Conflict of Interest

There was no conflict of interest. 


\section{References}

[1]Lee P, Hu Y, Chen P, Huang Y, Hsueh P. Are children less susceptible to COVID-19? Journal of Microbiology, Immunology and Infection.2020; DOI: 10.1016/j.jmii.2020.02.011

[2]Lu Q, Shi Y. Coronavirus disease (COVID-19) and neonate: What neonatologist need to know. J Med Virol. 2020; DOI: 10.1002/jmv.25740

[3]Wei M, Yuan J, Liu Y, Fu T, Yu X, Zhang ZJ. Novel Coronavirus Infection in Hospitalized Infants Under 1 Year of Age in China. JAMA.2020; DOI: 10.1001/jama.2020.2131

[4]Kam KQ, Yung CF, Cui L, Lin TPR, Mak TM, Maiwald M, et al. A Well Infant with Coronavirus Disease 2019 (COVID-19) with High Viral Load. Clin Infect Dis. 2020; DOI: 10.1093/cid/ciaa201

[5]Xia W, Shao J, Guo Y, Peng X, Li Z, Hu D. Clinical and CT features in pediatric patients with COVID-19 infection: Different points from adults. Pediatr Pulmonol. 2020; DOI:10.1002/ppul.24718

[6]Li W, Cui H, Li K, Fang Y, Li S. Chest computed tomography in children with COVID-19 respiratory infection. Pediatr Radiol. Pediatr Radiol. 2020; DOI:10.1007/s00247-020-04656-7

[7]Lin C, Ding Y, Xie B, Sun Z, Li X, Chen Z, et al. Asymptomatic novel coronavirus pneumonia patient outside Wuhan: The value of CT images in the course of the disease. Clin Imaging. 2020;63:7-9.

[8]Hu Z, Song C, Xu C, Jin G, Chen Y, Xu X, et al. Clinical characteristics of 24 asymptomatic infections with COVID-19 screened among close contacts in Nanjing, China. Sci China Life Sci. 2020; DOI:10.1007/s11427-020-1661-4

[9]National Health Commission of China. Diagnosis and Treatment Procotol for COVID-19. 7th edition, 2020. http://www.nhc.gov.cn/yzygj/s7653p/202003/46c9294a7dfe4cef80dc7f5912eb1989.shtml. accessed 4th Mar 2020.

[10]Shi H, Han X, Jiang N, Cao Y, Alwalid O, Gu J, et al. Radiological findings from 81 patients with COVID-19 pneumonia in Wuhan, China: a descriptive study. Lancet Infect Dis. 2020;DOI:10.1016/S1473-3099(20)30086-4

[11]Ai T, Yang Z, Hou H, Zhan C, Chen C, Lv W, et al. Correlation of Chest CT and RT-PCR Testing in Coronavirus Disease 2019 (COVID-19) in China: A Report of 1014 Cases. Radiology. 2020;DOI:10.1148/radiol.2020200642

[12]Shen K, Yang Y, Wang T, Zhao D, Jiang Y, Jin R, et al. Diagnosis, treatment, and prevention of 2019 novel coronavirus infection in children: experts' consensus statement. World J Pediatr. 2020;DOI:10.1007/s12519-020-00343-7 
[13]Chen N, Zhou M, Dong X, Qu J, Gong F, Han Y, et al. Epidemiological and clinical characteristics of 99 cases of 2019 novel coronavirus pneumonia in Wuhan, China: a descriptive study. Lancet. 2020;395(10223):507-513.

[14]Wang D, Hu B, Hu C, Zhu F, Liu X, Zhang J, et al. Clinical Characteristics of 138 Hospitalized Patients With 2019 Novel Coronavirus-Infected Pneumonia in Wuhan, China. JAMA. 2020;

DOI:10.1001/jama.2020.1585

[15]Lu R, Zhao X, Li J, Niu P, Yang B, Wu H, et al. Genomic characterisation and epidemiology of 2019 novel coronavirus: implications for virus origins and receptor binding. Lancet. 2020;395(10224):565-574.

[16]Xie X, Chen J, Wang X, Zhang F, Liu Y. Age- and gender-related difference of ACE2 expression in rat lung. Life Sci. 2006;78(19):2166-2171.

[17]Ling Y, Xu SB, Lin YX, Tian D, Zhu ZQ, Dai FH, et al. Persistence and clearance of viral RNA in 2019 novel coronavirus disease rehabilitation patients. Chin Med J (Engl). 2020;

DOI:10.1097/CM9.0000000000000774.

\section{Table}

Table 1 the differences of demographic, clinical and CT positive ratio in the two groups

\begin{tabular}{|llll|}
\hline & $\begin{array}{l}\text { Asymptomatic group } \\
\text { N (\%) }\end{array}$ & $\begin{array}{l}\text { Symptomatic group } \\
\mathrm{N}(\%)\end{array}$ & 0.245 \\
\hline sex & & & \\
\hline $\mathrm{m}$ & $3(75.0)$ & $1(25.0)$ & 0.092 \\
\hline $\mathrm{f}$ & $4(28.6)$ & & \\
\hline age & & $8(57.1)$ & 0.245 \\
\hline$<=3$ years & $0(0)$ & $6(42.9)$ & \\
\hline$>3$ years & $4(100)$ & & 0.541 \\
\hline diagnostic time & & $8(57.1)$ & \\
\hline$<=3$ days & $4(100)$ & $6(42.9)$ & \\
\hline$>3$ days & $0(0)$ & & \\
\hline${ }^{\square}$ CT positive ratio & & $3(23.1)$ & \\
\hline negative & $4(100)$ & & \\
\hline positive & $0(0)$ & & \\
\hline
\end{tabular}


CT, computed tomography; ${ }^{\square}$ one case with no available CT images; another susceptible case was designated to positive subset, the same as negative subset or omitted.

\section{Figures}
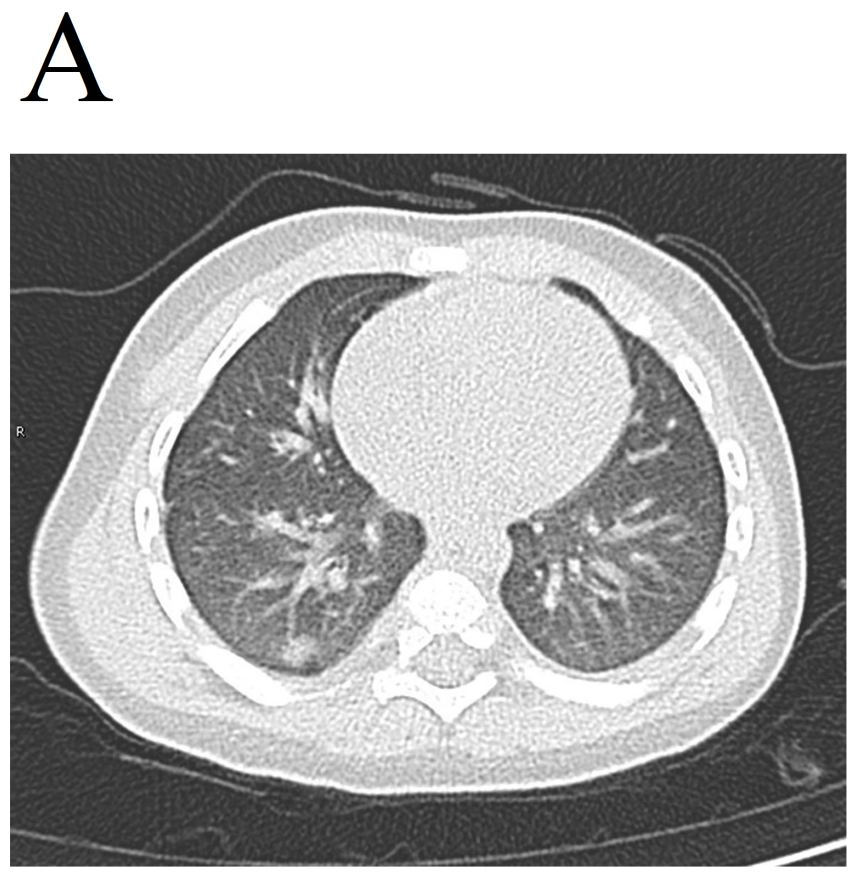

$\mathrm{B}$

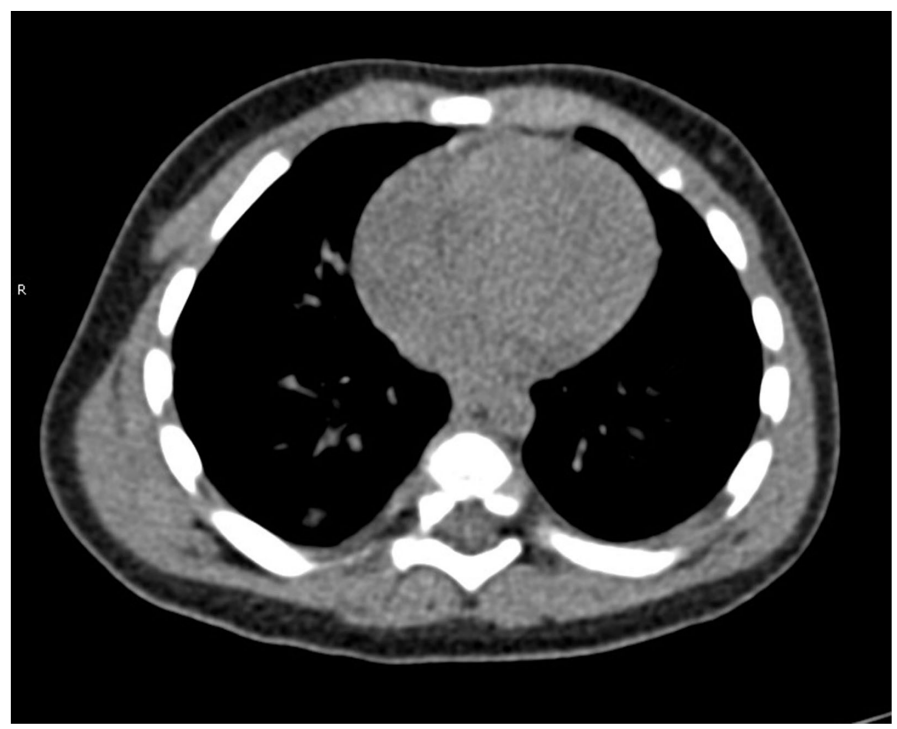

Figure 1

10 months 17 days $\mathrm{m} 4$ days fever admitted to hospital with presumptive influenza $A$ virus co-infection. An ill-fine patchy infiltration displayed in the basal segments of bilateral inferior lobes, respectively $(a, b)$. Air-trapping sign was also seen in the right inferior lobe. 


\section{$\mathrm{C}$}

$\mathrm{D}$
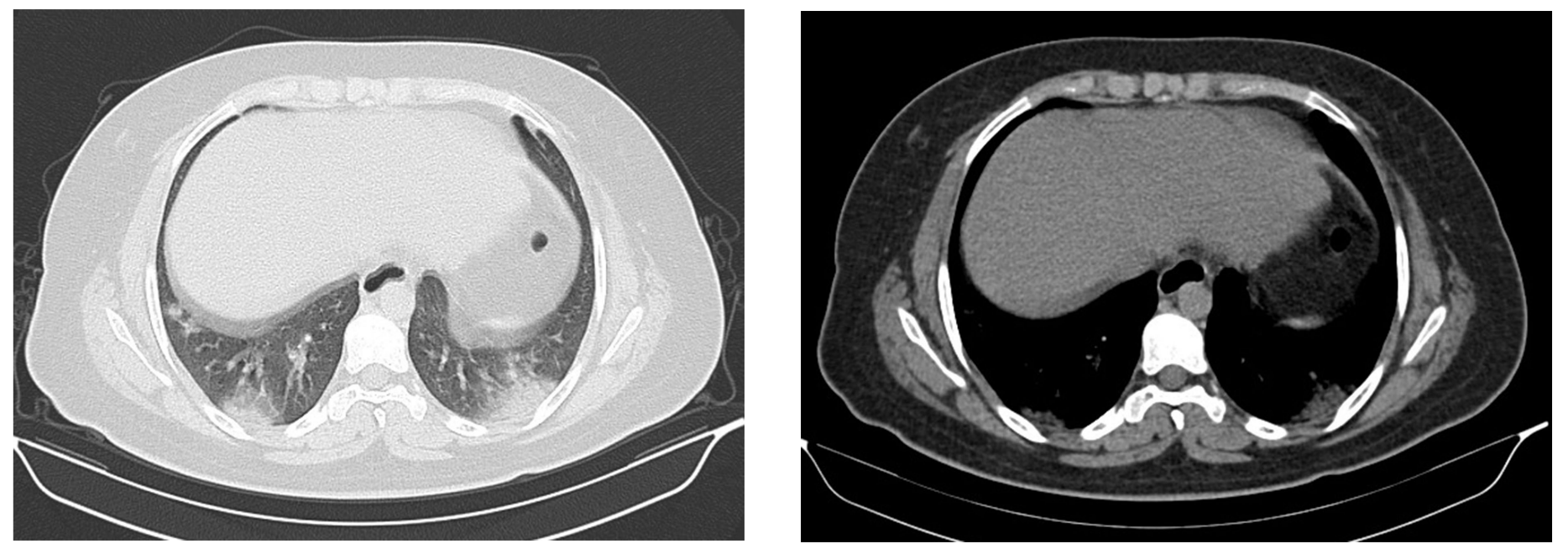

\section{Figure 2}

13 years $f 2$ days cough of phlegm admitted to hospital. A patchy infiltration displayed in the left superior lobe while an ill-fine ground-glass opacity was in the same lobe. Multiple, symmetrical ill-fine patchy consolidation with halo sign displayed in bilateral inferior lobes(c,d).

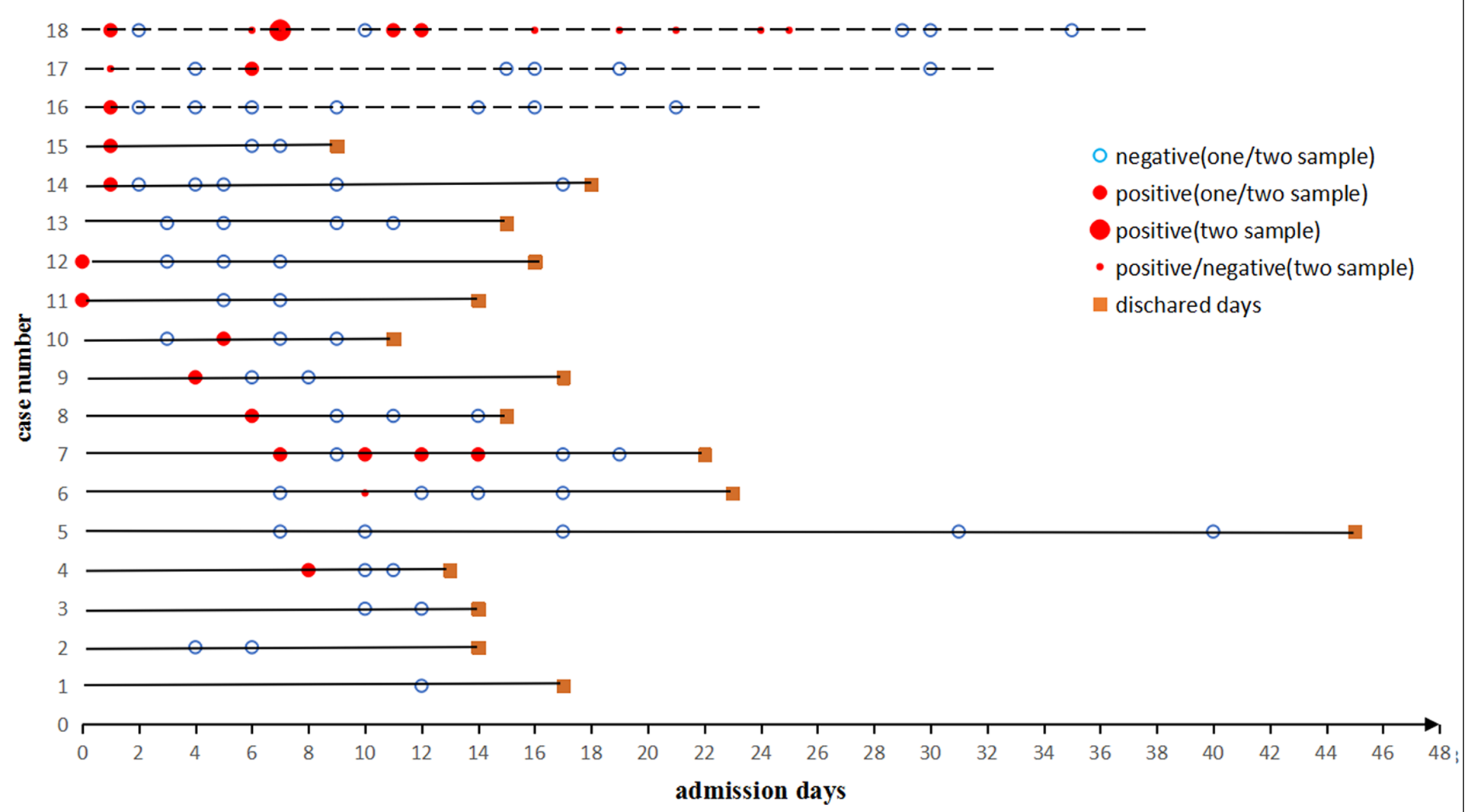


Figure 3

Figure 3 it showed new coronavirus nucleic acid detection results in different cases on different hospitalized day

\section{Supplementary Files}

This is a list of supplementary files associated with this preprint. Click to download.

- coverletter.doc 